\title{
Genetic compatibility between Anopheles lesteri from Korea and Anopheles paraliae from Thailand
}

\author{
Kritsana Taai', Visut Baimai ${ }^{2}$, Atiporn Saeung1, Sorawat Thongsahuan ${ }^{3}$, Gi-Sik Min ${ }^{4}$, \\ Yasushi Otsuka ${ }^{5}$, Mi-Hyun Park , Masako Fukuda ${ }^{5,6}$, Pradya Somboon', Wej Choochote ${ }^{1 /+}$ \\ 'Department of Parasitology, Faculty of Medicine, Chiang Mai University, Chiang Mai, Thailand \\ ${ }^{2}$ Department of Biology and Centre for Vectors and Vector-Borne Diseases, Faculty of Science, Mahidol University, Bangkok, Thailand \\ ${ }^{3}$ Faculty of Veterinary Science, Prince of Songkla University, Songkhla, Thailand \\ ${ }^{4}$ Department of Biological Sciences, Inha University, Incheon, South Korea ${ }^{5}$ Department of Infectious Disease Control, Faculty of Medicine \\ ${ }^{6}$ Research Promotion Project, Oita University, Hasama, Oita, Japan
}

To assess differentiation and relationships between Anopheles lesteri and Anopheles paraliae we established three and five iso-female lines of An. lesteri from Korea and An. paraliae from Thailand, respectively. These isolines were used to investigate the genetic relationships between the two taxa by crossing experiments and by comparing DNA sequences of ribosomal DNA second internal transcribed spacer (ITS2) and mitochondrial DNA cytochrome c oxidase subunit I (COI) and subunit II (COII). Results of reciprocal and F-hybrid crosses between An. lesteri and An. paraliae indicated that they were compatible genetically producing viable progenies and complete synaptic salivary gland polytene chromosomes without inversion loops in all chromosome arms. The pairwise genetic distances of ITS2, COI and COII between these morphological species were 0.040, 0.007-0.017 and 0.008-0.011, respectively. The specific species status of An. paraliae in Thailand and/or other parts of the continent are discussed.

Key words: Anopheles lesteri - Anopheles paraliae - crossing experiments - second internal transcribed spacer - cytochrome $c$ oxidase subunit I - cytochrome $c$ oxidase subunit II

The Anopheles hyrcanus Group has a wide range of distributions extending from Iberia in Europe to East and Southeast Asia, including some of the off-lying islands of the Indian and Pacific Oceans. Up until now, at least 27 species have been reported within this group (Harrison \& Scanlon 1975, Harbach 2010). It is well known that some species of the Hyrcanus Group are involved in transmission of human diseases, particularly in the Oriental and contiguous parts of the eastern Palaearctic regions. For example, human malaria Plasmodium vivax was detected in Anopheles sinensis, Anopheles lesteri, Anopheles kleini, Anopheles pullus and Anopheles belenrae (Harrison 1973, Ree et al. 2001, Whang et al. 2002, Ma \& Xu 2005, Lee et al. 2007, Joshi et al. 2009, 2011, Rueda et al. 2010). Moreover, Brugia malayi was found in An. sinensis and An. lesteri (Sasa 1976) while Anopheles peditaeniatus was infected with Japanese encephalitis virus (Zhang 1990, Kanojia et al. 2003). In addition, some members of the Hyrcanus Group have also been considered as economic pests of cattle because of their vicious biting-behaviour and ability to transmit cervid filariae of the genus Setaria (Reid et al. 1962, Reid 1968, Harrison \& Scanlon 1975).

Financial support: The Thailand Research Fund (to WC and AS) (TRF Senior Research Scholar: RTA5480006, TRF Advanced Research Scholar: BRG5380021), Royal Golden Jubilee PhD Program (to WC and KT) (PHD/0297/2551), Faculty of Medicine Endowment Fund, Chiang Mai University

+Corresponding author: choochote.wej@gmail.com

Received 24 August 2012

Accepted 26 November 2012
An. lesteri has been found in the Philippines (type locality) and the Palaearctic regions (China, Korea and Japan) whereas Anopheles paraliae has been detected in the coastal areas of Peninsular Malaysia, Sabah, Sarawak, Brunei, Vietnam and Thailand. However, the taxonomic ambiguity of An. paraliae was raised as early as 1959. Morphologically, An. paraliae has a narrower apical fringe spot on the wing compared with that of An. lesteri, but their immature stages can not be distinguished from each other. Consequently, An. paraliae was considered to be a subspecies, An. lesteri paraliae, by earlier authors (Sandosham 1959, Reid 1963, 1968, Harrison \& Scanlon 1975). Nevertheless, this subspecies was elevated subsequently to species status, i.e., $A n$. paraliae, based on distinct characteristics of the adult wings and immature habitats (brackish and/or peaty water) (Harrison et al. 1991). Yet there is no evidence of genetic differences between An. lesteri and An. paraliae. This article presents the results of crossing experiment and cytogenetic study of these two species and comparative DNA sequence analyses of the second internal transcribed spacer (ITS2) of ribosomal DNA (rDNA), the cytochrome $c$ oxidase subunit I (COI) and subunit II (COII) of mitochondrial DNA (mtDNA).

\section{MATERIALS AND METHODS}

Collection sites - Samples of An. lesteri from Korea were caught in a vinyl tent in a rice paddy field of the district of So Rae, Incheon City, northern of the province of Gyeonggi. The An. paraliae specimens from Thailand were obtained by using cow-baited traps in three localities, i.e., district of Damnoen Saduak, province of Ratchaburi, district of Pak Panang, province of Nakhon 
Si Thammarat and district of Hat Yai, province of Songkhla (Table I). Species identification using $\mathrm{F}_{1}$-progeny of each iso-female line followed the keys of Rueda et al. (2005) and Rattanarithikul et al. (2006). The distinctive characteristics of wings to separate An. lesteri from An. paraliae are illustrated in Fig. 1.

Establishment of iso-female lines - Three and five iso-female lines of An. lesteri (ilG1, ilG2, ilG3) and $A n$. paraliae (ipR1, ipR2, ipN1, ipS1, ipS2), respectively, were established successfully using the methods of Choochote et al. (1983) and Kim et al. (2003). They have been maintained in colonies for more than five consecutive generations in our laboratory and they were used for crossing experiments and comparative DNA sequence analyses.

Crossing experiments - One iso-female line (ilG1) of An. lesteri and three iso-female lines (ipR1, ipN1, ipS1) of An. paraliae were arbitrarily selected for crossing experiments to determine post-mating reproductive isolation by employing the techniques previously reported by Saeung et al. (2007). Study on salivary gland polytene chromosomes of 4th instar larvae of $\mathrm{F}_{1}$-hybrids from the crosses followed the techniques of White et al. (1975) and Kanda (1979).

DNA extraction and amplification - Individual $\mathrm{F}_{1}-$ progeny adult females of each iso-female line of An. lesteri (ilG1, ilG2, ilG3) and An. paraliae (ipR1, ipR2, ipN1, $\mathrm{ipS1}$, ipS2) were used for DNA extraction and amplification. Molecular analysis of ITS2, COI, COII was performed to determine intraspecific sequence variation in An. lesteri and An. paraliae. Genomic DNA was extracted from adult mosquitoes using the DNeasy ${ }^{\circledR}$ Blood and Tissue Kit (Qiagen). Primers for amplification of ITS2, $\mathrm{COI}$ and COII regions followed the methods of Saeung et

TABLE I

Locations, code of iso-female lines of Anopheles lesteri and Anopheles paraliae and their GenBank accessions

\begin{tabular}{|c|c|c|c|c|c|c|c|}
\hline \multirow[b]{2}{*}{ Location } & \multirow{2}{*}{$\begin{array}{l}\text { Code of } \\
\text { isoline }^{a}\end{array}$} & \multirow{2}{*}{$\begin{array}{l}\text { Length of } \\
\text { ITS2 } \\
\text { (bp) }\end{array}$} & \multicolumn{5}{|c|}{ GenBank accession } \\
\hline & & & DNA region & ITS2 & COI & COII & Reference \\
\hline \multicolumn{8}{|l|}{ An. lesteri } \\
\hline Korea: Gyeonggi & $\mathrm{ilG1}^{a}$ & 448 & ITS2, COI, COII & AB733020 & AB733028 & AB733036 & This paper \\
\hline Gyeonggi & ilG2 & 448 & ITS2, COI, COII & AB733021 & AB733029 & AB733037 & This paper \\
\hline \multirow[t]{2}{*}{ Gyeonggi } & ilG3 & 448 & ITS2, COI, COII & AB733022 & AB733030 & AB733038 & This paper \\
\hline & - & 448 & ITS2 & EU789791 & - & - & Park et al. (2008) \\
\hline Japan & - & 448 & ITS2 & AB159606 & - & - & $\begin{array}{c}\text { K Sawabe et } \\
\text { al., unpublished } \\
\text { observations }\end{array}$ \\
\hline Philippines & - & 438 & ITS2 & AY375469 & - & - & $\begin{array}{l}\text { Wilkerson et al. } \\
\qquad(2003)\end{array}$ \\
\hline \multicolumn{8}{|c|}{ An. lesteri (= Anopheles anthropophagus) } \\
\hline \multirow[t]{2}{*}{ China } & - & 448 & ITS2 & AY803792 & - & - & $\begin{array}{c}\text { Ma and Yang } \\
\text { (2005) }\end{array}$ \\
\hline & - & 438 & ITS2 & AY375467 & - & - & $\begin{array}{l}\text { Wilkerson et al. } \\
\qquad(2003)\end{array}$ \\
\hline \multicolumn{8}{|l|}{ An. paraliae } \\
\hline Thailand: Ratchaburi & $\mathrm{ipR} 1^{a}$ & 448 & ITS2, COI, COII & AB733023 & AB733031 & AB733039 & This paper \\
\hline Ratchaburi & ipR2 & 448 & ITS2, COI, COII & AB733024 & AB733032 & AB733040 & This paper \\
\hline Nakhon Si Thammarat & $\mathrm{ipN}^{a}$ & 448 & ITS2, COI, COII & AB733025 & AB733033 & AB733041 & This paper \\
\hline Songkhla & $\mathrm{ipS1}^{a}$ & 448 & ITS2, COI, COII & AB733026 & AB733034 & AB733042 & This paper \\
\hline Songkhla & ipS2 & 448 & ITS2, COI, COII & AB733027 & AB733035 & AB733043 & This paper \\
\hline \multicolumn{8}{|l|}{ Anopheles sinensis } \\
\hline Thailand & - & 469 & ITS2 & AY130473 & - & - & Min et al. (2002) \\
\hline Korea & - & 469 & ITS2, COI, COII & EU789790 & GQ265918 & AY130464 & $\begin{array}{l}\text { Min et al. (2002), } \\
\text { Park et al. (2008), } \\
\text { Joshi et al. (2009) }\end{array}$ \\
\hline \multicolumn{8}{|l|}{ Anopheles peditaeniatus } \\
\hline Thailand & - & 463 & ITS2, COI, COII & AB539061 & AB539069 & AB539077 & Choochote (2011) \\
\hline
\end{tabular}

$a$ : used in crossing experiments; COI: cytochrome $c$ oxidase subunit I; COII: cytochrome $c$ oxidase subunit II; ITS2: second internal transcribed spacer. 
al. (2007). Polymerase chain reaction (PCR) reaction was performed in total $20 \mu \mathrm{L}$ volume containing $0.5 \mathrm{U}$ Ex Taq (Takara), 1X Ex Taq buffer, $2 \mathrm{mM}$ of $\mathrm{MgCl}_{2}, 0.2 \mathrm{mM}$ of each dNTP, $0.25 \mu \mathrm{M}$ of each primer and $1 \mu \mathrm{L}$ of the extracted DNA. For ITS2, the conditions for amplification consisted of initial denaturation at $94^{\circ} \mathrm{C}$ for $1 \mathrm{~min}, 30 \mathrm{cy}$ cles at $94^{\circ} \mathrm{C}$ for $30 \mathrm{sec}, 55^{\circ} \mathrm{C}$ for $30 \mathrm{sec}$ and $72^{\circ} \mathrm{C}$ for $1 \mathrm{~min}$ and a final extension at $72^{\circ} \mathrm{C}$ for $5 \mathrm{~min}$. The amplification profile of $\mathrm{COI}$ and $\mathrm{COII}$ comprised initial denaturation at $94^{\circ} \mathrm{C}$ for $1 \mathrm{~min}, 30$ cycles at $94^{\circ} \mathrm{C}$ for $30 \mathrm{sec}, 50^{\circ} \mathrm{C}$ for 30 sec and $72^{\circ} \mathrm{C}$ for $1 \mathrm{~min}$ and a final extension at $72^{\circ} \mathrm{C}$ for $5 \mathrm{~min}$. The amplified products were subjected to electrophoresis in a $1.5 \%$ agarose gel and stained with ethidium bromide. Finally, the PCR products were purified using the QIAquick ${ }^{\circledR}$ PCR Purification Kit (Qiagen) and their sequences directly determined using the BigDye ${ }^{\circledR}$ Terminator Cycle Sequencing Kit and 3130 genetic analyzer (Applied Biosystems). The sequence data of this paper have been deposited in the DDBJ/EMBL/GenBank nucleotide sequence database under accessions AB733020AB733043. The ITS2, COI and COII sequences obtained from this study were also compared with deposited sequences available through GenBank (Table I).
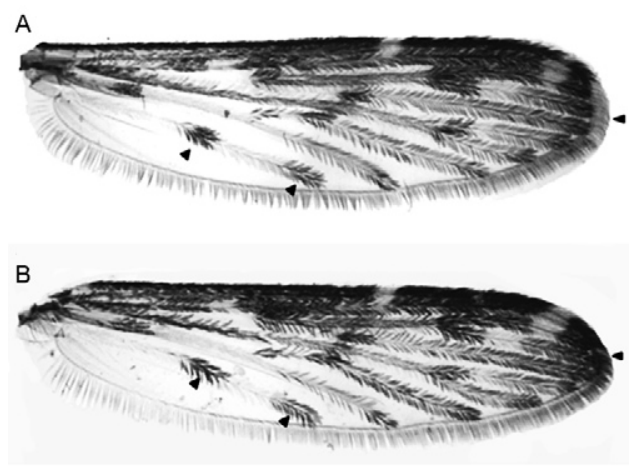

c
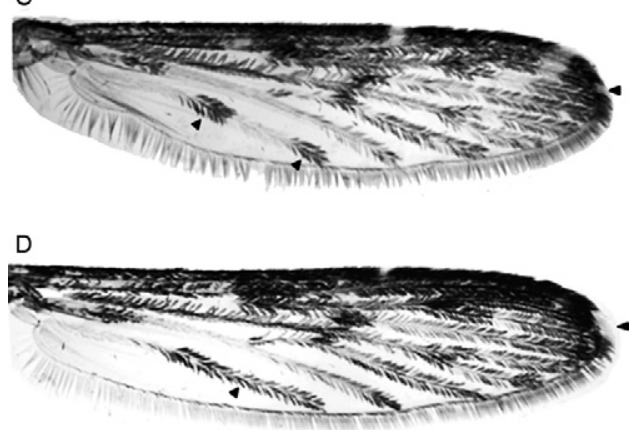

Fig. 1A: wing of Anopheles lesteri from Korea showing wide pale fringe spot extending from tip of vein $\mathrm{R}_{1}$ to $\mathrm{R}_{4+5}$ and two dark spots on anal vein (1A); B-D: wings of Anopheles paraliae from Thailand showing very narrow pale fringe spot at tip of vein $\mathrm{R}_{2}$, and two dark spots on $1 \mathrm{~A}$ similar to that of $A n$. lesteri (B), narrow fringe spot at tip of vein $\mathrm{R}_{2}$ and two dark spots on $1 \mathrm{~A}(\mathrm{C})$ and moderated fringe spot extending from tip of vein $R_{1-3}$ and one dark spot on $1 A(D)$.
Sequencing alignment and phylogenetic analysis Sequences of ITS2, COI and COII were aligned using the CLUSTALW multiple alignment program (Thompson et al. 1994). Gap sites were excluded from the following analysis. The Kimura two-parameter method was used to calculate genetic distances (Kimura 1980). Construction of neighbour-joining (NJ) trees (Saitou \& Nei 1987) and the bootstrap test with 1,000 replications were performed with the MEGA version 4.0 program (Tamura et al. 2007). Bayesian analysis was conducted with MrBayes 3.2 (Ronquist et al. 2012) by using two replicates of one million generations with the nucleotide evolutionary model, GTR+I, which was selected by MrModeltest version 2.3 (Evolutionary Biology Centre, Uppsala University, 2004) as the best-fit model for ITS2, $\mathrm{COI}$ and COII. Bayesian posterior probabilities were calculated from the consensus tree after excluding the first $25 \%$ trees as burnin.

\section{RESULTS}

Crossing experiments - Details of hatchability, pupation, emergence and adult sex-ratio of parental, reciprocal and $\mathrm{F}_{1}$-hybrid crosses between An. lesteri from Korea and An. paraliae from Thailand are shown in Table II. All crosses yielded viable progenies through the $\mathrm{F}_{2}$-generations. No evidence of genetic incompatibility and/or post-mating reproductive isolation was observed among these crosses (repeated twice: experiments 2 and 3, data are not shown). The salivary gland polytene chromosomes of $\mathrm{F}_{1}$-hybrid larvae from all crosses showed complete synapsis without inversion loops in all chromosome arms (Fig. 2).

Sequence analysis of ITS2, COI and COII regions The level of genetic distance and number of base substitutions between sequences of the three regions are presented in Tables III-V. Analysis of the ITS2 sequence revealed no intraspecific sequence variation among the three and five iso-female lines of An. lesteri and An. paraliae, respectively. Comparison of ITS2 sequences indicated that An. lesteri differed from An. paraliae by 16 base substitutions (pairwise distance $=0.040$ ). In addition, three iso-female lines of An. lesteri from Korea were identical with An. lesteri from China (= Anopheles anthropophagus) (AY803732, AY375467), Japan (AB159606) and Korea (EU789791), but they differed from those of the Philippines (AY375469) by three base substitutions (pairwise distance $=0.007$ ). The average percentages of base composition for the ITS2 sequence of the eight iso-female lines ( 3 of An. lesteri from Korea and 5 of An. paraliae from Thailand) were A: $29.9 \%$ (29.2-30.5\%), T: $24.2 \%(23.6-24.9 \%)$, G: $25.2 \%$ (25$25.4 \%$ ) and C: $20.8 \%$ (20.6-20.9\%). Percentage of GC content was 46\% in An. lesteri (448 bp) and 45\% in An. paraliae (448 bp). All eight sequences differed markedly from An . sinensis (pairwise distance $=0.321-0.338$ ) and An. peditaeniatus (pairwise distance $=0.550-0.566$ ) (Table III). The analysis of COI (658 bp) among the eight iso-female lines revealed four-nine base substitutions (pairwise distance $=0.007-0.017$ ). On the contrary, $A n$. lesteri and An. paraliae showed significant differences 


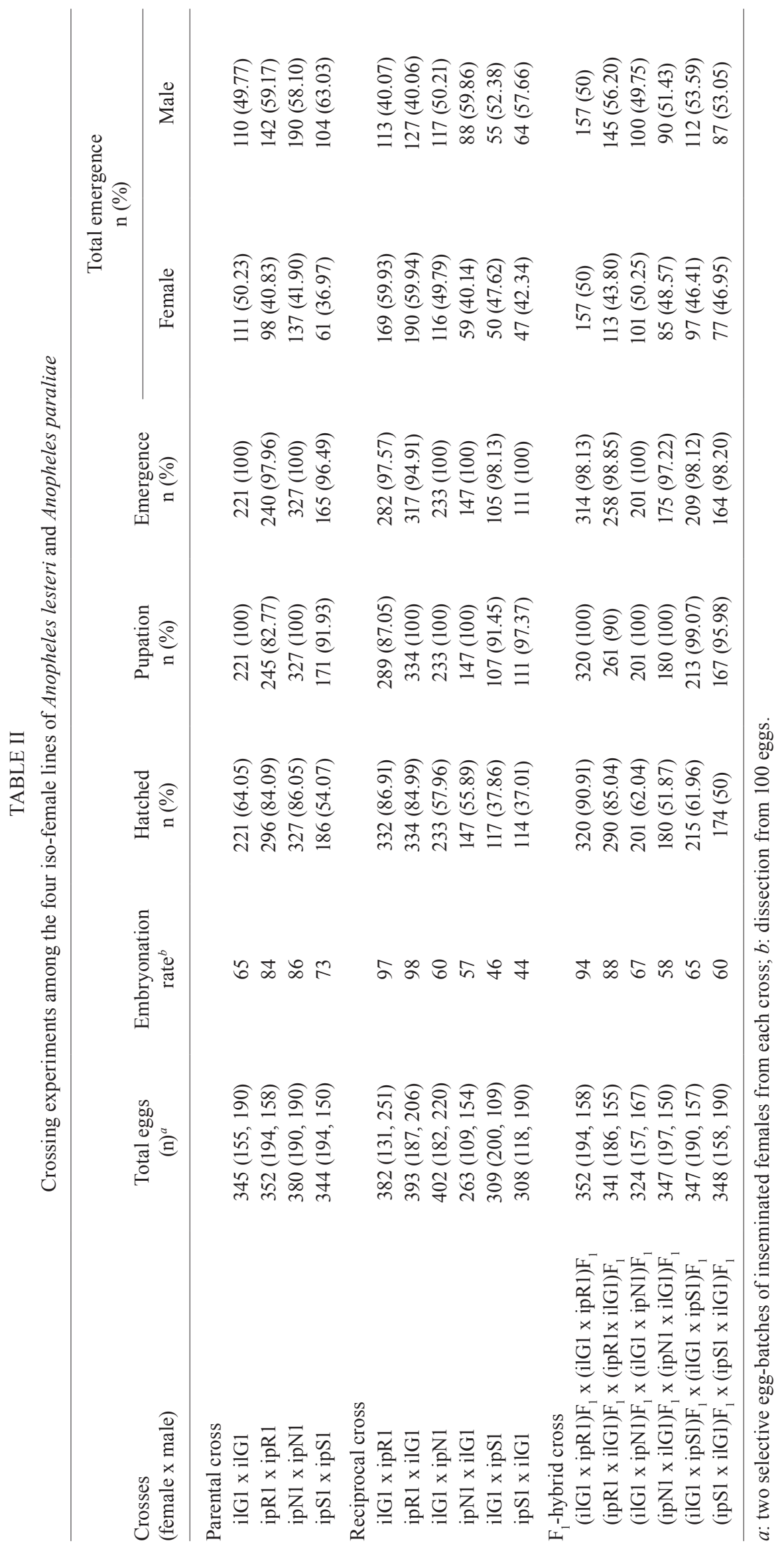



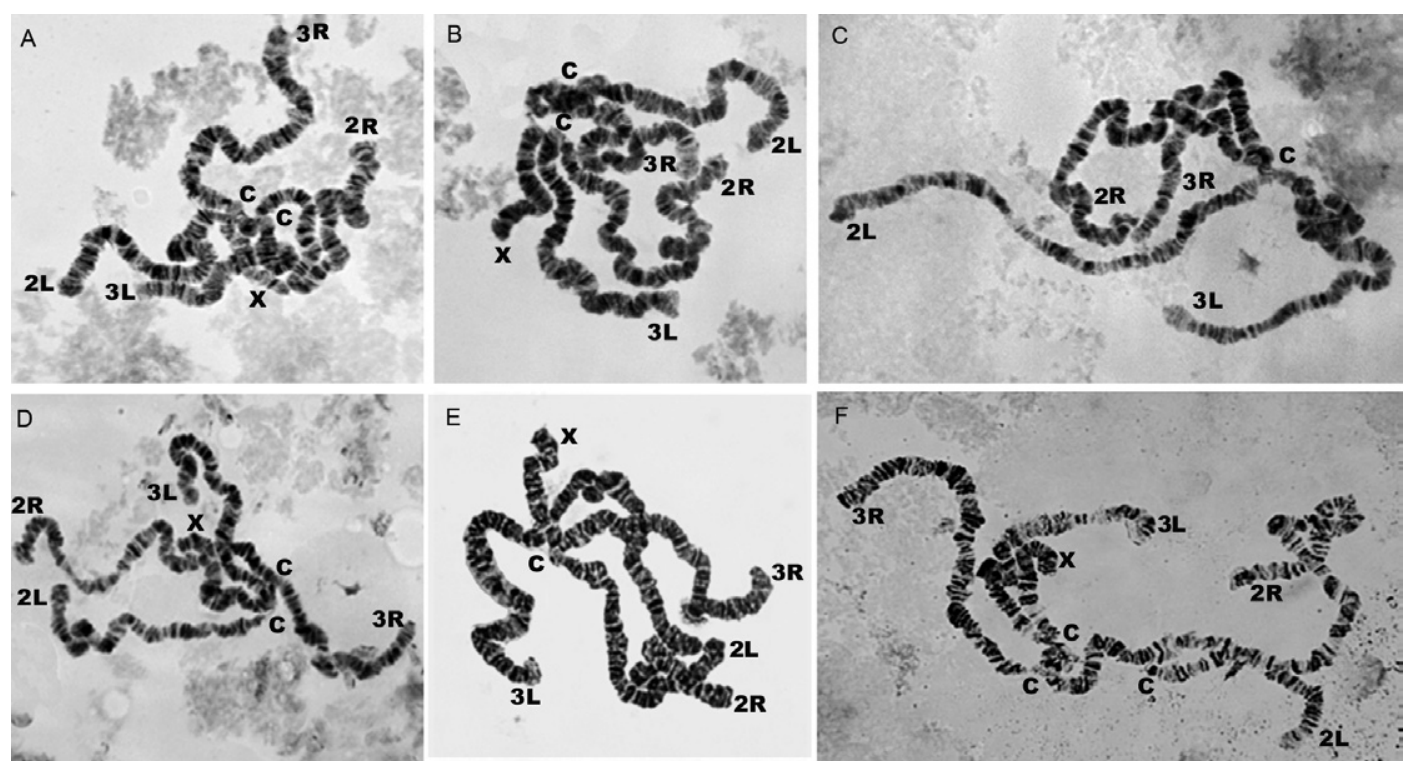

Fig. 2: complete synapsis in all arms of salivary gland polytene chromosome of $\mathrm{F}_{1}$-hybrid larvae of crosses between Anopheles lesteri and Anopheles paraliae. A: ilG1 female x ipR1 male; B: ipR1 female x ilG1 male; C: ilG1 female x ipN1 male; D: ipN1 female x ilG1 male; E: ilG1 female x ipS1 male; F: ipS1 female x ilG1 male.

from An. sinensis (pairwise distance $=0.034-0.042)$ and An. peditaeniatus (pairwise distance $=0.037-0.041)(\mathrm{Ta}-$ ble IV). The analysis of COII (685 bp) among the eight iso-female lines revealed five-seven base substitutions (pairwise distance $=0.008-0.011$ ). These two species also showed significant differences from $A n$. sinensis (pairwise distance $=0.039$ ) and An. peditaeniatus (pairwise distance $=0.031-0.036)($ Table V).

Phylogenetic analysis - The NJ and Bayesian trees of An. lesteri, An. paraliae, An. sinensis and An. peditaeniatus were constructed based on the ITS2, COI and COII sequences (Fig. 3). For ITS2, An. lesteri $(\mathrm{n}=8)$ and An. paraliae $(\mathrm{n}=5)$ were clustered in each monophyletic and well separated from An. sinensis and An. peditaeniatus with high bootstrap values (93-100\%) in both $\mathrm{NJ}$ and Bayesian trees. The trees indicated that An. lesteri was more closely related to An. paraliae (average genetic distances $=0.038$ ) than to the other species. Further, lower sequence divergences (0.000-0.002) were found within the population of each species. For COI and COII, the trees showed that An. lesteri was more closely related to An. paraliae than to the other species with low level of average genetic distances $(0.008-0.011)$ for both regions, while very low genetic distances $(0.003-0.005)$ were obtained within the population of each species.

\section{DISCUSSION}

Crossing experiments using iso-female lines of closely related species of the Oriental Anopheles have proven to be a robust systematic procedure for clarifying species status, for example, Anopheles minimus and Anopheles aconitus (Harrison 1980, Sucharit \& Choochote 1982), Anopheles annularis and Anopheles philippinensis (Choochote et al. 1984), Anopheles nivipes and An. philippinensis (Klein et al. 1984) and An. minimus and Anopheles flavirostris (Somboon et al. 2000). These methods are useful for solving taxonomic problems of some sibling species complexes, e.g., Anopheles dirus (Baimai et al. 1987), Anopheles maculatus (Thongwat et al. 2008), An. minimus (Somboon et al. 2001, 2005, Choochote et al. 2002) and Anopheles barbirostris (Saeung et al. 2007, 2008, Suwannamit et al. 2009). Likewise, the status of subspecies or cytological races of Anopheles can be elucidated by the same approach of cytogenetic study as exemplified in An. pullus (= Anopheles yatsushiroensis) (Park et al. 2003), Anopheles vagus (Choochote et al. 2002), An. aconitus (Junkum et al. 2005), An. sinensis (Choochote et al. 1998, Min et al. 2002, Park et al. 2008), An. barbirostris species A1 (Saeung et al. 2007, Suwannamit et al. 2009), Anopheles campestrislike taxon (Thongsahuan et al. 2009) and An. peditaeniatus (Choochote 2011). Our findings in this study showed no post-mating reproductive isolation between An. lesteri from Korea and An. paraliae from Thailand. These results were clearly supported by cytological evidence and DNA analysis. Thus, complete synapsis of salivary gland polytene chromosomes without inversion loops along the entire lengths of all chromosome arms was observed in the $\mathrm{F}_{1}$-hybrid larvae between An. lesteri and An. paraliae which strongly indicated genetic compatibility between them.

Analysis of ITS2 sequences of An. lesteri from Korea (ilG1, ilG2, ilG3) revealed identical sequences to An. lesteri from China (=An. anthropophagus), Japan and Korea (genetic distance $=0.000$ ), although they showed little difference from those of the Philippines (genetic distance $=0.007$ ) (Wilkerson et al. 2003, Ma \& Yang 2005, Park et al. 2008, K Sawabe et al., unpublished observations). Our results were in agreement with those previously reported by $\mathrm{Ma}$ and $\mathrm{Xu}$ (2005). Moreover, the low level of pair- 
TABLE III

Genetic distance and number of nucleotide substitutions in second internal transcribed spacer sequences among Anopheles lesteri, Anopheles paraliae, Anopheles sinensis and Anopheles peditaeniatus

\begin{tabular}{|c|c|c|c|c|c|c|c|c|c|c|c|c|c|c|c|c|}
\hline Taxon & 1 & 2 & 3 & 4 & 5 & 6 & 7 & 8 & 9 & 10 & 11 & 12 & 13 & 14 & 15 & 16 \\
\hline 1 ilG1 & - & 0 & 0 & 16 & 16 & 16 & 16 & 16 & 0 & 0 & 0 & 0 & 3 & 107 & 108 & 163 \\
\hline 2 ilG2 & 0.000 & - & 0 & 16 & 16 & 16 & 16 & 16 & 0 & 0 & 0 & 0 & 3 & 107 & 108 & 163 \\
\hline 3 ilG3 & 0.000 & 0.000 & - & 16 & 16 & 16 & 16 & 16 & 0 & 0 & 0 & 0 & 3 & 107 & 108 & 163 \\
\hline $4 \mathrm{ipR} 1$ & 0.040 & 0.040 & 0.040 & - & 0 & 0 & 0 & 0 & 16 & 16 & 16 & 16 & 17 & 110 & 111 & 160 \\
\hline $5 \mathrm{ipR} 2$ & 0.040 & 0.040 & 0.040 & 0.000 & - & 0 & 0 & 0 & 16 & 16 & 16 & 16 & 17 & 110 & 111 & 160 \\
\hline $6 \mathrm{ipN} 1$ & 0.040 & 0.040 & 0.040 & 0.000 & 0.000 & - & 0 & 0 & 16 & 16 & 16 & 16 & 17 & 110 & 111 & 160 \\
\hline 7 ips1 & 0.040 & 0.040 & 0.040 & 0.000 & 0.000 & 0.000 & - & 0 & 16 & 16 & 16 & 16 & 17 & 110 & 111 & 160 \\
\hline $8 \mathrm{ipS} 2$ & 0.040 & 0.040 & 0.040 & 0.000 & 0.000 & 0.000 & 0.000 & - & 16 & 16 & 16 & 16 & 17 & 110 & 111 & 160 \\
\hline 9 anthC (AY803792) & 0.000 & 0.000 & 0.000 & 0.040 & 0.040 & 0.040 & 0.040 & 0.040 & - & 0 & 0 & 0 & 3 & 107 & 108 & 163 \\
\hline 10 anthC (AY375467) & 0.000 & 0.000 & 0.000 & 0.040 & 0.040 & 0.040 & 0.040 & 0.040 & 0.000 & - & 0 & 0 & 3 & 107 & 108 & 163 \\
\hline 11 lesJ (AB159606) & 0.000 & 0.000 & 0.000 & 0.040 & 0.040 & 0.040 & 0.040 & 0.040 & 0.000 & 0.000 & - & 0 & 3 & 107 & 108 & 163 \\
\hline 12 lesK (EU789791) & 0.000 & 0.000 & 0.000 & 0.040 & 0.040 & 0.040 & 0.040 & 0.040 & 0.000 & 0.000 & 0.000 & - & 3 & 107 & 108 & 163 \\
\hline 13 lesP (AY375469) & 0.007 & 0.007 & 0.007 & 0.042 & 0.042 & 0.042 & 0.042 & 0.042 & 0.007 & 0.007 & 0.007 & 0.007 & - & 105 & 106 & 163 \\
\hline $14 \operatorname{sinK}($ EU789790) & 0.321 & 0.321 & 0.321 & 0.334 & 0.334 & 0.334 & 0.334 & 0.334 & 0.321 & 0.321 & 0.321 & 0.321 & 0.314 & - & 3 & 154 \\
\hline $15 \operatorname{sinT}(\mathrm{AY} 130473)$ & 0.325 & 0.325 & 0.325 & 0.338 & 0.338 & 0.338 & 0.338 & 0.338 & 0.325 & 0.325 & 0.325 & 0.325 & 0.318 & 0.007 & - & 155 \\
\hline 16 pedT (AB539061) & 0.566 & 0.566 & 0.566 & 0.550 & 0.550 & 0.550 & 0.550 & 0.550 & 0.566 & 0.566 & 0.566 & 0.566 & 0.567 & 0.520 & 0.525 & - \\
\hline
\end{tabular}

above triangle: number of nucleotide substitutions; below triangle: genetic distance.

\section{TABLE IV}

Genetic distance and number of nucleotide substitutions in cytochrome $c$ oxidase subunit I sequences among Anopheles lesteri, Anopheles paraliae, Anopheles sinensis and Anopheles peditaeniatus

\begin{tabular}{lcccccccccc}
\hline Taxon & 1 & 2 & 3 & 4 & 5 & 6 & 7 & 8 & 9 & 10 \\
\hline 1 ilG1 & - & 1 & 2 & 7 & 6 & 6 & 8 & 7 & 22 & 22 \\
2 ilG2 & 0.002 & - & 3 & 8 & 7 & 7 & 9 & 8 & 21 & 21 \\
3 ilG3 & 0.004 & 0.006 & - & 5 & 4 & 4 & 6 & 5 & 20 & 22 \\
4 ipR1 & 0.013 & 0.015 & 0.009 & - & 1 & 1 & 5 & 0 & 19 & 21 \\
5 ipR2 & 0.011 & 0.013 & 0.007 & 0.002 & - & 0 & 4 & 1 & 18 & 20 \\
6 ipN1 & 0.011 & 0.013 & 0.007 & 0.002 & 0.000 & - & 4 & 1 & 18 & 20 \\
7 ipS1 & 0.015 & 0.017 & 0.011 & 0.009 & 0.007 & 0.007 & - & 5 & 22 & 20 \\
8 ipS2 & 0.013 & 0.015 & 0.009 & 0.000 & 0.002 & 0.002 & 0.009 & - & 19 & 21 \\
9 sinK (GQ265918) & 0.042 & 0.040 & 0.038 & 0.036 & 0.034 & 0.034 & 0.042 & 0.036 & - & 29 \\
10 PedT (AB539069) & 0.041 & 0.039 & 0.041 & 0.039 & 0.037 & 0.037 & 0.037 & 0.039 & 0.055 & - \\
\hline
\end{tabular}

above triangle: number of nucleotide substitutions; below triangle: genetic distance.

wise distance (0.040) detected between An. lesteri from Korea and An. paraliae from Thailand, based on ITS2 sequences, was in accordance with previous reports of different groups of Anopheles, e.g., the Anopheles gambiae complex (0.4-1.6\%) (Paskewitz et al. 1993), Anopheles dunhami and Anopheles nuneztovari (mean genetic distance $=0.025)($ Ruiz et al. 2010), Anopheles fluviatilis $\mathrm{S}$ and An. minimus $\mathrm{C}$ (pairwise distance $=0.036)($ Singh et al. 2006), Anopheles kunmingensis and Anopheles liangshanensis (pairwise distance $=0.0381$ ) and An. pullus (= An. yatsushiroensis) and Anopheles junlianensis (pairwise distance $=0.03081$ ) (Hwang 2007). Currently, Calado et al. (2008) showed that An. nuneztovari A is not conspecific with An. nuneztovari B/C based on COI sequences (genetic distance $=0.00818-0.02071$ ) and $A n$. dunhami has been reported as new record in the Brazilian Amazon by comparing sequences with those of An. nuneztovari A (genetic distance $=0.01436-0.03343$ ). Similarly, comparative sequences for COI and COII between An. lesteri and An. paraliae revealed low average genetic distance between them (0.008-0.011). Despite such low genetic distances, phylogenetic trees seem to 
TABLE V

Genetic distance and number of nucleotide substitutions in cytochrome $c$ oxidase subunit II sequences among Anopheles lesteri, Anopheles paraliae, Anopheles sinensis and Anopheles peditaeniatus

\begin{tabular}{lcccccccccc}
\hline Taxon & 1 & 2 & 3 & 4 & 5 & 6 & 7 & 8 & 9 & 10 \\
\hline $1 \mathrm{ilG1}$ & - & 1 & 0 & 5 & 5 & 5 & 6 & 5 & 25 & 20 \\
$2 \mathrm{ilG2}$ & 0.002 & - & 1 & 6 & 6 & 6 & 7 & 6 & 25 & 20 \\
$3 \mathrm{ilG3}$ & 0.000 & 0.002 & - & 5 & 5 & 5 & 6 & 5 & 25 & 20 \\
$4 \mathrm{ipR} 1$ & 0.008 & 0.009 & 0.008 & - & 0 & 0 & 5 & 0 & 25 & 22 \\
$5 \mathrm{ipR} 2$ & 0.008 & 0.009 & 0.008 & 0.000 & - & 0 & 5 & 0 & 25 & 22 \\
$6 \mathrm{ipN1}$ & 0.008 & 0.009 & 0.008 & 0.000 & 0.000 & - & 5 & 0 & 25 & 22 \\
$7 \mathrm{ipS1}$ & 0.009 & 0.011 & 0.009 & 0.008 & 0.008 & 0.008 & - & 5 & 25 & 23 \\
$8 \mathrm{ipS2}$ & 0.008 & 0.009 & 0.008 & 0.000 & 0.000 & 0.000 & 0.008 & - & 25 & 22 \\
$9 \mathrm{sinK}$ (AY130464) & 0.039 & 0.039 & 0.039 & 0.039 & 0.039 & 0.039 & 0.039 & 0.039 & - & 29 \\
$10 \mathrm{PedT}$ (AB539077) & 0.031 & 0.031 & 0.031 & 0.034 & 0.034 & 0.034 & 0.036 & 0.034 & 0.045 & - \\
\hline
\end{tabular}

above triangle: number of nucleotide substitutions; below triangle: genetic distance.

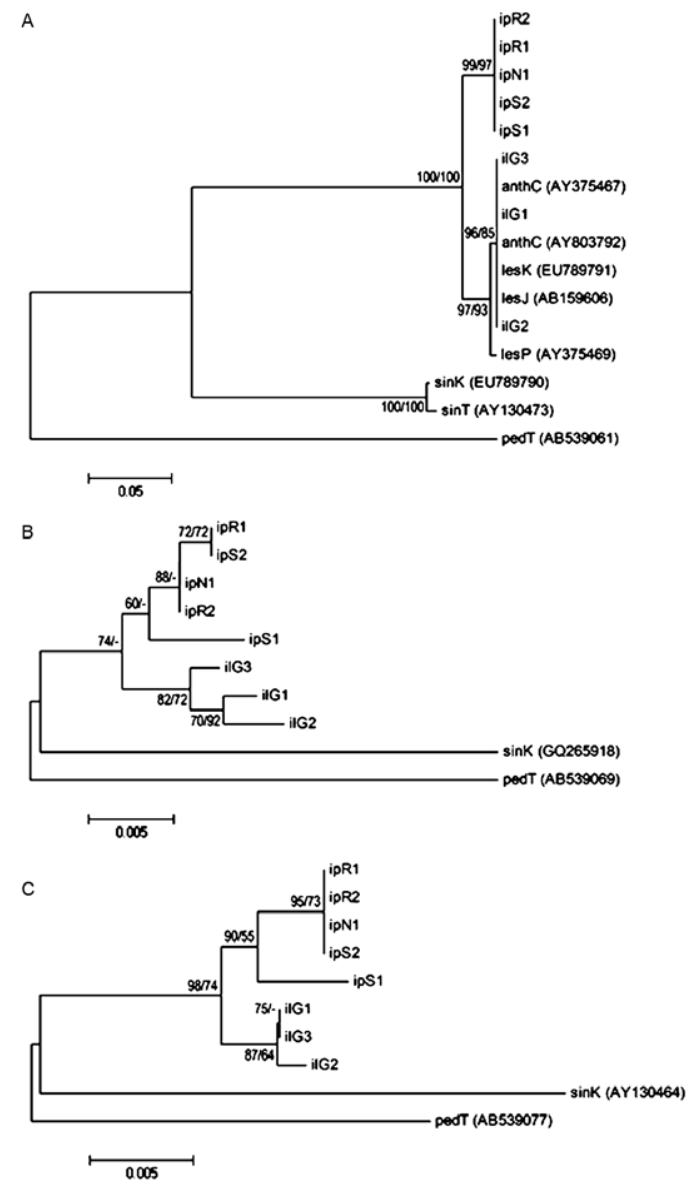

Fig. 3: neighbour-joining (NJ) trees inferred from sequences of three loci. A: second internal transcribed spacer; B: cytochrome $c$ oxidase subunit I (COI); C: COII of Anopheles paraliae, Anopheles lesteri, Anopheles sinensis and Anopheles peditaeniatus. Numbers on branches are bootstrap values (\%) of NJ analysis and Bayesian posterior probabilities (\%). A hyphen (-) shows that the branch did not appear in majority rule $(50 \%)$ consensus trees of Bayesian analysis. Branch lengths are proportional to genetic distance (scale bar). indicate that An. lesteri and An. paraliae were well separated from each other with NJ and Bayesian analyses for three regions, except for the Bayesian tree of COI. Although these two species were distinguished apparently by DNA sequence analysis, they obviously showed genetic compatibility by crossing experiments. Controversy over taxonomic problems with respect to fullfledged species, sibling species and subspecies within a taxon of Anopheles has occurred when only data of comparative DNA sequence analyses of certain specific genomic regions were used as first hand criteria for separating them. For example, An. fluviatilis $\mathrm{S}$ was considered a synonym of An. minimus $\mathrm{C}$ based on comparison of the D3 domains of 28S (28S-D3) (Harbach 2004, Garros et al. 2005, Chen et al. 2006). However, Singh et al. (2006) carried out molecular analysis on ITS2 and D2-D3 domains of 28S rDNA regions of An. fluviatilis $\mathrm{S}$ and An. minimus $\mathrm{C}$. The authors suggested that these Anopheles species did not deserve synonymous status. Hence, crossing experiments between An. fluviatilis $\mathrm{S}$ and An. minimus $\mathrm{C}$ using iso-female lines are essential prior to a definite conclusion as to their conspecificity. Our studies using crossing experiments between An. lesteri from Korea and An. paraliae from Thailand together with data on species distributions, morphological variants, cytology and comparative DNA sequence analyses have clearly indicated that they are conspecific within the taxon An. lesteri. Additionally, the population genetic structure will be studied further in order to evaluate the gene flow among An. lesteri and An. paraliae populations before definitely concluding that An. lesteri is a synonym of An. paraliae.

\section{ACKNOWLEDGEMENTS}

To Dr Niwes Nantachit, Dean of the Faculty of Medicine, Chiang Mai University, for his interest in this research.

\section{REFERENCES}

Baimai V, Andre RG, Harrison BA, Kijchalao U, Panthusiri L 1987. Crossing and chromosomal evidence for two additional sibling spe- 
cies within the taxon Anopheles dirus Peyton and Harrison (Diptera: Culicidae) in Thailand. Proc Entomol Soc Wash 89: 157-166.

Calado DC, Foster PG, Bergo ES, dos Santos CLS, Galardo AKR, Sallum MAM 2008. Resurrection of Anopheles goeldii from synonymy with Anopheles nuneztovari (Diptera, Culicidae) and a new record for Anopheles dunhami in the Brazilian Amazon. Mem Inst Oswaldo Cruz 103: 791-799.

Chen B, Butlin RK, Pedro PM, Wang XZ, Harbach RE 2006. Molecular variation, systematics and distribution of the Anopheles fluviatilis complex in southern Asia. Med Vet Entomol 20: 33-43.

Choochote W 2011. Evidence to support karyotypic variation of the mosquito Anopheles peditaeniatus in Thailand. J Insect Sci 11: 10.

Choochote W, Abeyewickreme W, Sucharit S, Tumrasvin W, Rongsriyam Y 1984. Laboratory hybridization of Anopheles philippinensis and Anopheles annularis in Thailand. J Parasit Trop Med Ass Thailand 7: 7-11.

Choochote W, Jitpakdi A, Rongsriyam Y, Komalamisra N, Pitasawat B, Palakul K 1998. Isoenzyme study and hybridization of two forms of Anopheles sinensis (Diptera: Culicidae) in Northern Thailand. Southeast Asian J Trop Med Public Health 29: 841-847.

Choochote W, Jitpakdi A, Sukontason K, Chaithong U, Wongkamchai S, Pitasawat B, Jariyapan N, Suntaravitun T, Rattanachanpichai E, Sukontason K, Leemingsawat S, Rongsriyam Y 2002. Intraspecific hybridization of two karyotypic forms of Anopheles vagus (Diptera: Culicidae) and the related egg surface topography. Southeast Asian J Trop Med Public Health 33 (Suppl. 3): 29-35.

Choochote W, Sucharit S, Abeywickreme W 1983. Experiments in crossing two strains of Anopheles barbirostris van der Wulp 1884 (Diptera: Culicidae) in Thailand. Southeast Asian J Trop Med Public Health 14: 204-209.

Garros C, Harbach RE, Manguin S 2005. Morphological assessment and molecular phylogenetics of the Funestus and Minimus Groups of Anopheles (Cellia). J Med Entomol 42: 522-536.

Harbach RE 2004. The classification of genus Anopheles (Diptera: Culicidae): a working hypothesis of phylogenetic relationships. Bull Entomol Res 95: 537-553.

Harbach RE 2010. Mosquito taxonomic inventory. Anopheles classification. Available from: mosquito-taxonomic-inventory.info/ anophelesclassification.

Harrison BA 1973. A lectotype designation and description for Anopheles (An.) sinensis Wiedemann 1828, with a discussion of the classification and vector status of this and some other Oriental Anopheles. J Am Mosq Control Assoc 5: 1-13.

Harrison BA 1980. Medical entomology studies: XIII. The Myzomyia series of Anopheles (Cellia) in Thailand with emphasis on intrainterspecific variations (Diptera: Culicidae). Contributions of the American Entomological Institute 17: 1-195.

Harrison BA, Rattanarithikul R, Peyton EL, Mongolpanya K 1991. Taxonomic changes, revised occurrence records and notes on the Culicidae of Thailand and neighboring countries. J Am Mosq Control Assoc 22: 196-227.

Harrison BA, Scanlon JE 1975. Medical entomology studies II. The subgenus Anopheles in Thailand (Diptera: Culicidae). Contributions of the American Entomological Institute 12: 1-307.

Hwang UW 2007. Revisited ITS2 phylogeny of Anopheles (Anopheles) hyrcanus group mosquitoes: re-examination of unidentified and misidentified ITS2 sequences. Parasitol Res 101: 885-894.

Joshi D, Choochote W, Park MH, Kim JY, Kim TS, Suwonkerd W, Min GS 2009. The susceptibility of Anopheles lesteri to infection with Korean strain of Plasmodium vivax. Malar J 8: 42.
Joshi D, Kim JY, Choochote W, Park MH, Min GS 2011. Preliminary vivax malaria vector competence for three members of the Anopheles hyrcanus group in the Republic of Korea. J Am Mosq Control Assoc 27: 312-314.

Junkum A, Jitpakdi A, Jariyapan N, Komalamisra N, Somboon P, Suwonkerd W, Saejeng A, Bates PA, Choochote W 2005. Evidence to support two conspecific cytological races on Anopheles aconitus in Thailand. J Vector Ecol 30: 213-224.

Kanda T 1979. Improved techniques for the preparation of polytene chromosome for some anopheline mosquitoes. Mosq News 39: 568-574.

Kanojia PC, Shetty PS, Geevarghese G 2003. A long-term study on vector abundance \& seasonal prevalence in relation to the occurrence of Japanese encephalitis in Gorakhpur district, Uttar Pradesh. Indian J Med Res 117: 104-110.

Kim SJ, Choochote W, Jitpakdi A, Junkum A, Park SJ, Min GS 2003. Establishment of a self-mating mosquito colony of Anopheles sinensis from Korea. Korean J Entomol 33: 267-271.

Kimura MA 1980. Simple method for estimating evolutionary rates of base substitution through comparative studies of nucleotide sequences. J Mol Evol 16: 111-120.

Klein TA, Harrison BA, Baimai V, Phunkitchar V 1984. Hybridization evidence supporting separate species status for Anopheles nivipes and Anopheles philippinensis. Mosq News 44: 466-470.

Lee WJ, Klein TA, Kim HC, Choi YM, Yoon SH, Chang KS, Chong ST, Lee IY, Jones JW, Jacobs JS, Sattabongkot J, Park JS 2007. Anopheles kleini, Anopheles pullus and Anopheles sinensis: potential vectors of Plasmodium vivax in the Republic of Korea. J Med Entomol 44: 1086-1090.

Ma Y, Xu J 2005. The hyrcanus group of Anopeles (Anopheles) in China (Diptera: Culicidae): species discrimination and phylogenetic relationships inferred by ribosomal DNA internal transcribed spacer 2 sequences. J Med Entomol 42: 610-619.

Ma Y, Yang P 2005. Taxonomic study on Anopheles anthropophagus from China (Diptera: Culicidae): inferred by morphology, chromosome karyotype and molecular markers. Kun Chong Fen Lei Xиe Bao 27: 199-208.

Min GS, Choochote W, Jitpakdi A, Kim SJ, Kim W, Jung J, Junkum A 2002. Intraspecific hybridization of Anopheles sinensis (Diptera: Culicidae) strains from Thailand and Korea. Mol Cells 14: 198-204.

Park MH, Choochote W, Kim SJ, Somboon P, Saeung A, Tuetan B, Tsuda Y, Takagi M, Joshi D, Ma Y, Min GS 2008. Nonreproductive isolation among four allopatric strains of Anopheles sinensis in Asia. J Am Mosq Control Assoc 24: 489-495.

Park SJ, Choochote W, Jitpakdi A, Junkum A, Kim SJ, Jariyapan N, Park JW, Min GS 2003. Evidence for a conspecific relationship between two morphologically and cytologically different forms of Korean Anopheles pullus mosquito. Mol Cells 16: 354-360.

Paskewitz SM, Wesson DM, Collins FH 1993. The internal transcribed spacers of ribosomal DNA in five members of the Anopheles gambiae species complex. Insect Mol Biol 2: 247-257.

Rattanarithikul R, Harrison BA, Harbach RE, Panthusiri P, Coleman RE 2006. Illustrated keys to the mosquitoes of Thailand IV. Anopheles. Southeast Asian J Trop Med Public Health 37 (Suppl. 2): 1-128.

Ree HI, Hwang UW, Lee IY, Kim TE 2001. Daily survival and human blood index of Anopheles sinensis, the vector species of malaria in Korea. J Am Mosq Control Assoc 17: 67-72.

Reid JA 1963. Notes on anopheline mosquitoes from Malaya with descriptions of three new species. Ann Trop Med Parasitol 57: 97-116. 
Reid JA 1968. Anopheline mosquitoes of Malaya and Borneo. Stud Inst Med Res Malaya 31: 1-520.

Reid JA, Wilson T, Ganapathipillai A 1962. Studies on filariasis in Malaya: the mosquito vectors of periodic Brugia malayi in northwest Malaya. Ann Trop Med Parasitol 56: 323-336.

Ronquist F, Teslenko M, van der Mark P, Ayres DL, Darling A, Höhna S, Larget B, Liu L, Suchard MA, Huelsenbeck JP 2012. MrBayes 3.2: efficient Bayesian phylogenetic inference and model choice across a large model space. Syst Biol 61: 539-542.

Rueda LM, Li C, Kim HC, Klein TA, Foley DH, Wilkerson RC 2010. Anopheles belenrae, a potential vector of Plasmodium vivax in the Republic of Korea. J Am Mosq Control Assoc 26: 430-432.

Rueda LM, Wilkerson RC, Li C 2005. Anopheles (Anopheles) lesteri Baisas and $\mathrm{Hu}$ (Diptera: Culicidae): neotype designation and description. Proc Entomol Soc Wash 107: 604-662.

Ruiz F, Linton YM, Ponsonby DJ, Conn JE, Herrera M, Quiñones ML, Vélez ID, Wilkerson RC 2010. Molecular comparison of topotypic specimens confirms Anopheles (Nyssorhynchus) dunhami Causey (Diptera: Culicidae) in the Colombian Amazon. Mem Inst Oswaldo Cruz 105: 899-903.

Saeung A, Baimai V, Otsuka Y, Rattanarithikul R, Somboon P, Junkum A, Tuetun B, Takaoka H, Choochote W 2008. Molecular and cytogenetic evidence of three sibling species of the Anopheles barbirostris form A (Diptera:Culicidae) in Thailand. Parasitol Res 102: 499-507.

Saeung A, Otsuka Y, Baimai V, Somboon P, Pitasawat B, Tuetun B, Junkum A, Takaoka H, Choochote W 2007. Cytogenetic and molecular evidence for two species in the Anopheles barbirostris complex (Diptera: Culicidae) in Thailand. Parasitol Res 101: 1337-1344.

Saitou N, Nei M 1987. The neighbor-joining method: a new method for reconstructing phylogenetic trees. Mol Biol Evol 4: 406-425.

Sandosham AA 1959. Malariology, with special reference to Malaya, University of Malaya Press, Singapore, 322 pp.

Sasa M 1976. Human filariasis: a global survey of epidemiology and control, University of Tokyo Press, Tokyo, 819 pp.

Singh OP, Chandra D, Nanda N, Sharma SK, Htun PT, Adak T, Subbarao SK, Dash AP 2006. On the conspecificity of Anopheles fluviatilis species S with Anopheles minimus species C. J Biosci 31: 671-677.

Somboon P, Thongwat D, Choochote W, Walton C, Takagi M 2005. Crossing experiments of Anopheles minimus species $\mathrm{C}$ and putative species E. J Am Mosq Control Assoc 21: 5-9.
Somboon P, Tuno N, Tsuda Y, Takagi M 2000. Evidence of the specific status of Anopheles flavirostris (Diptera: Culicidae). J Med Entomol 37: 476-479.

Somboon P, Walton C, Sharpe RG, Higa Y, Tuno N, Tsuda Y, Takagi M 2001. Evidence for a new sibling species of Anopheles minimus from the Ryukyu Archipelago, Japan. J Am Mosq Control Assoc 17: 98-113.

Sucharit S, Choochote W 1982. Hybridization of Anopheles minimus and Anopheles aconitus (Diptera: Culicidae) in Thailand. J Med Entomol 19: 209-292.

Suwannamit S, Baimai V, Otsuka Y, Saeung A, Thongsahuan S, Tuetun B, Apiwathnasorn C, Jariyapan N, Somboon P, Takaoka H, Choochote W 2009. Cytogenetic and molecular evidence for an additional new species within the taxon Anopheles barbirostris (Diptera: Culicidae) in Thailand. Parasitol Res 104: 905-918.

Tamura K, Dudley J, Nei M, Kumar S 2007. MEGA4: Molecular Evolution Genetics Analysis (MEGA) software version 4.0. Mol Biol Evol 24: 1596-1599.

Thompson JD, Higgins DG, Gibson TJ 1994. CLUSTALW: improving the sensitivity of progressive multiple sequence alignment through sequence weighting, positions-specific gap penalties and weight matrix choice. Nucleic Acids Res 22: 4673-4680.

Thongsahuan S, Baimai V, Otsuka Y, Saeung A, Tuetun B, Jariyapan N, Suwannamit S, Somboon P, Jitpakdi A, Takaoka H, Choochote W 2009. Karyotypic variation and geographic distribution of Anopheles campestris-like (Diptera: Culicidae) in Thailand. Mem Inst Oswaldo Cruz 104: 558-566.

Thongwat D, Morgan K, O'loughlin MS, Walton C, Choochote W, Somboon P 2008. Crossing experiment supporting the specific status of Anopheles maculatus chromosomal form K. J Am Mosq Control Assoc 24: 194-202.

Whang IJ, Jung J, Park JK, Min GS, Kim W 2002. Intragenomic length variation of the ribosomal DNA intergenic spacer in a malaria vector, Anopheles sinensis. Mol Cells 14: 158-162.

White GB, Coluzzi M, Zahar AR 1975. Review of cytogenetic studies on anopheline vectors of malaria. Available from: apps.who.int/ iris/bitstream/10665/65716/1/WHO_MAL_75.849.pdf.

Wilkerson RC, Li C, Rueda LM, Kim HC, Klein TA, Song GH, Strickman D 2003. Molecular confirmation of Anopheles (Anopheles) lesteri from the Republic of South Korea and its genetic identity with An. (Ano.) anthropophagus from China (Diptera: Culicidae). Zootaxa 378: 1-14.

Zhang HL 1990. The natural infection rate of mosquitoes by Japanese encephalitis B virus in Yunnan Province. Zhonghua Yu Fang Yi Xue Za Zhi 24: 265-267. 